\title{
Recovery of Hunger Sensations Associated with Low Preprandial Blood Glucose: An Easy Exit from Diabetes?
}

\author{
Mario Ciampolini*, Gaia Cecchi \\ Preventive Gastroenterology, Department of Pediatrics, Università di Firenze, Florence, Italy \\ Email: "mlciampolini@fastwebnet.it
}

Received 30 April 2016; accepted 28 May 2016; published 31 May 2016

Copyright (C) 2016 by authors and Scientific Research Publishing Inc.

This work is licensed under the Creative Commons Attribution International License (CC BY). http://creativecommons.org/licenses/by/4.0/

(c) (i) Open Access

\section{Abstract}

Background: Obesity, diabetes, asthma, autism, birth defects, dyslexia, attention deficit-hyperactivity disorder and schizophrenia have increased in children in the last half century. These increases may depend on the widespread, well known error in energy balance: the unremitting addition of fat at any will (decision) to eat. In most (60\%) but not all people, the decision arises as conditioned before energy exhaustion of the energy available from previous meals. After meal suspension for few hours (up to $\mathbf{4 8}$ hours), healthy subjects identified the arousal of sensations of hunger that we named Initial Hunger (IH). After this identification, subjects distinguished IH from conditioned sensations before subsequent meals by mental comparison of the current arousal with the remembered IH. BG decreased to $76.6 \pm 3.7 \mathrm{mg} / \mathrm{dL}$ and hunger sensations (Initial hunger, IH) arose spontaneously and corresponded to the complete exhaustion of the previous meals. Objective: Not Insulin Dependent (NID) diabetic people differ from fattening people in this: after meal suspension, they do not develop any hunger sensation nor the associated low blood glucose (BG). Methods: Meal suspension lets IH arise and after no arousal, reduction of energy intake. The two subjects consumed meals that provided at least 20 grams of animal protein and up to one $\mathrm{kg}$ of not- starchy vegetable (NSV) for 6 to 12 months. At reappearance of IH, we implemented an Initial Hunger Meal Pattern (IHMP). Results: We tried to implement IHMP training in two obese (BMI of 39 and 33) adults out of two consecutive recruitments of subjects who showed high fasting BG. We found an absence of BG decline to $76.6 \pm 3.7 \mathrm{mg} / \mathrm{dL}$ and an absence of any hunger sensation after eating suspension. Both subjects lost 13\% - 20\% of their body weight and recovered 76.6 $\pm 3.7 \mathrm{mg} / \mathrm{dL}$ of BG and hunger sensations, i.e., went off diabetes. IHMP maintained the decreased body weight in the subsequent months. Conclusion: Diabetes develops for inveterate conditioned intake (when previous energy intake has not been fully exhausted before meals), excessive fattening (with presumed excessive post-absorption emission of fatty acids from fatty tissues), permanent loss of BG decline to $76.6 \pm 3.7 \mathrm{mg} / \mathrm{dL}$ and permanent loss of physiological signals of

${ }^{*}$ Corresponding author.

How to cite this paper: Ciampolini, M. and Cecchi, G. (2016) Recovery of Hunger Sensations Associated with Low Preprandial Blood Glucose: An Easy Exit from Diabetes? Open Journal of Preventive Medicine, 6, 149-159.

http://dx.doi.org/10.4236/ojpm.2016.65014 
hunger. A healthy, non-diabetic life may be recovered by painless loss of weight up to $20 \%$. The body weight remained stable by implementing IHMP at reappearance of hunger sensations. This costs accurate energy intake planning instead of hunger endurance.

\author{
Keywords \\ Energy Balance, Energy Intake, Even Energy Balance, Blood Glucose, Even Blood Glucose, \\ Homeostasis, Fattening, Insulin Resistance, Diabetes
}

\title{
1. Introduction
}

After meal suspension and training, clinically healthy children and adults were always able to identify the sensations of Initial Hunger (IH) and learning their recognition [1]-[5]. Subjects regulated energy intake to three or four planned IH arousals, a pattern named as IH meal pattern (IHMP), and decreased energy density of meals for a better planning. They also increased physical activity to protect the lean body mass from lower energy intake [6]-[10]. Subjects' IH appeared to be as a physiological function that aroused when BG decreased toward $76.6 \pm 3.7 \mathrm{mg} / \mathrm{dL}$ in both children and adults [2] [7] [11]-[13]. At recruitment most adults had conditioned meals, and reported that their hunger aroused as conditioned sensations after deciding to eat (will to eat) [2]-[7]. After meal suspension for no more than 24 - 48 hours, these clinically healthy children and adults developed spontaneous IH and were able to distinguish the two sensations after adequate training. In our recruitment program, we encountered two diabetic obese subjects who denied having any hunger arousal within two starvation days. We aim to report their absent hunger arousal even after months of eating 300 to $400 \mathrm{kcal}$ per day and a large body weight loss. This presentation is preliminary in the prospective to solicit a larger study that may assure a definitive demonstration. Alimentary diabetes (NIDD) may be characterized, explained, or signaled by the absence of hunger arousal that is vital for animal life: as an assumption, maintenance of high BG for years may produce big fat and the abundance of fatty acid input into blood may suppress hunger for long time until conspicuous reduction of stored fat and correspondent reduction in fat input into the blood. Conspicuous loss of weight may recover the hunger sensations and a training to IHMP may eliminate the NIDD incapability of lowering BG. At this point, the NID diabetic people might consider themselves as healthy as about a third of investigated children and adults who show preprandial BG at $76.6 \pm 3.7 \mathrm{mg} / \mathrm{dL}$ by free choice [2] [3] [7].

\section{Materials and Methods}

\subsection{Research Design}

We assumed BG as an index of energy availability in blood and in all tissues [1 - 20] and conceived the preprandial BG measurements as a check to protect the subject from poorly manifested hypoglycemia and to assess energy balance between meals [9]. At IH arousal, the same background (BG) suggested that IH recognition was accurate. A sequence of low fasting BG meant an even energy balance, whereas a high preprandial BG suggested a positive energy imbalance even if preprandial BG was steady [13]-[16]. "Mean (preprandial) BG" from weekly diaries was stable across a week and after five months, the confidence interval being $4 \mathrm{mg} / \mathrm{dL}$ to 6 mg/dL [3] [7], but not across different individuals and different balance conditions [3] [7]. Thus Mean BG characterized the habitual level of energy availability, the individual customs in intake and balance. Mean BG was associated with resting metabolic rate, insulin resistance, microflora growth in duodenum and immune stimulation of all body tissues (overall inflammation) [12] [15]. In our program of recruitment (see) we found that 2 out of two consecutive diabetic, noninsulin dependent patients had lost the arousal of the physiological function of hunger as well as the possibility of BG declining to $76.6 \pm 3.7 \mathrm{mg} / \mathrm{dL}$. These losses suggested us to suspend energy intake. The intention was to obtain conspicuous body weight loss, decrease of fatty acid input into blood and recovery of $\mathrm{IH}$ as a physiological function, as well as of a BG decline to $76.6 \pm 3.7 \mathrm{mg} / \mathrm{dL}$ and, lastly, the construction of a IHMP meal pattern. This pattern is shown by about a third of healthy subjects at recruitment and may be considered healthy and also normal as freely chosen by a large minority. 


\subsection{Studies in Children}

We studied infants between 6 months and 3 years of age with chronic/recurrent diarrhea. Many were clinically healthy and 9 were undernourished. All were hospitalized in the Unity of Pediatric Gastroenterology in the Pediatric Department of the University of Florence for one or more days or even many months in follow-up studies up to twelve years between 1980 and 2000 [1]-[6]. We excluded food allergy by using the paper radioimmunosorbent test and by measurement of total IgE [1] [2]. We screened the feces of all infants for parasites and viral or bacterial pathogens. Those who were positive were excluded. C-reactive protein was normal. Celiac disease was excluded by measuring antibodies against tTG and/or intestinal biopsy. The group of diarrheic, malnourished, not celiac infants (2 to 15 months of age) was separately studied in a follow-up for two years [5].

\subsection{Studies in Adults}

After the first diagnoses of celiac disease, the Unit received and treated also adults. The adult recruitment opened the possibility of an evaluation of the infant training. The IHMP training might be useful to either only exit from diarrhea relapses or might even educate to a healthier way of life The local hospital ethics committee approved the investigations in compliance with the Declaration of Helsinki. Informed consent was obtained from parents for all the infants and directly from adult subjects. Subjects showed no morphological, physical or biochemical signs of organic disease [2] [3]. Subjects with impaired glucose tolerance (fasting plasma-glucose > $115 \mathrm{mg} / \mathrm{dL}(6.4 \mathrm{mmol} / \mathrm{l}))$, as well as subjects suffering from non-insulin dependent diabetes mellitus (NIDDM), celiac, inflammatory bowel, liver, heart, brain and kidney diseases were excluded from recruitment. Before recruitment, we prepared a list of blocks of 1 - 4 empty places. In a ratio of 1:3 blocks, we randomly assigned the blocks of empty places to either control or training groups by using Armitage odd and even random numbers. A dietician kept the list and subsequently assigned each recruited subject to the first empty list place. Control or training destination was revealed to the researchers after the first visit. Clinical assessments were performed at initial and final visits and twice in the intervening 4 - 7 months follow-up period. The assessments evaluated compliance, nutritional intake and the subject's clinical condition. Written diaries were kept for a week before each clinical visit to evaluate IH arousal 3 or 4 times a day, preprandial BG three times a day, and relative adaptations in energy and fiber intake and in hours spent either in bed or in a gym plus outdoors. The number of subjects for each study was calculated to find differences with a power of $95 \%$ and an alpha of 0.05 . Further details are reported in each published article. Between 1995 and 2000, overweight adults or adults with functional bowel disorders came to the Unit for diagnostic purposes (mainly for Celiac diagnosis) and for treatment and were eligible for the adult study on body weight and insulin sensitivity. A total of 181 subjects aged between 18 and 60, clinically healthy, were recruited for a study of effects on body weight by IHMP. We randomly assigned all subjects to controlled studies in which the primary output was weight [13]. Attrition (drop outs) was modest [17], always lower than $20 \%$. One-hundred and forty-nine adults completed the study on body weight and 120 adults completed a second study where the primary output was insulin sensitivity [7].

\subsection{Statistical Methods}

Preliminary work in similar patients found BMI in the intervention group to be 26.6 (SD 3.6) and in the control group 29.0 (SD 3.5) [18]. Based on these figures, our sample size calculations suggested that we need a minimum of 21 subjects in each comparison group to detect a difference of 2.0 in group means, with a power of $80 \%$ and a 1 sided alpha of 0.05 .Values are expressed as mean \pm SD. Twenty-one diarized BG measurements had a normal distribution around the mean. Confidence intervals were calculated to include $95 \%$ of measurements. [19] Stratification of 120 subjects by mean BG and search for the cutoff point at recruitment between subjects who significantly responded to "recognizing hunger" by mean BG and non-responders was discussed in the Statistics Department of the University of Firenze (see Acknowledgments). In the separate LBG (low) and HBG (high) subgroups, a logistic regression analysis investigated the association of the training and BG mean, Hb1c, insulin and BG AUCs, intakes, and anthropometric measures (trained vs untrained control groups) to overcome doubts on significance of multiple results. Collinearity diagnostics and residual analysis validated the statistical model. The significance of difference and correlation was set at $\mathrm{P}<0.05$ in these analyses. Yates test and two-tailed Student's t-test on paired or unpaired samples according to data requirements were used to analyze the significance of difference and two-tailed Student's t-test for correlation. The significance was set at $\mathrm{P}<0.05$ for single 
measurements and at $\mathrm{P}<0.025$ for the GTT insulin and BG AUCs [18]. The trials on wellbeing, nutrition, and cardiovascular risks comprised five to seven tests each. The significance was set at $\mathrm{P}<0.01$ for the outcome of a single measurement within these trials. The Bonferroni correction was applied when required in the evaluation of multiple comparison results [19]. In multiple analyses, the "<" symbol indicates the least significant P-value. Specially provided software was used to tabulate data for statistical analyses. Microsoft Excel and SAS (v 8; SAS Institute, Inc., Cary, NC) were used for data presentation and for statistical analyses.

\subsection{Initial Hunger}

Initial Hunger ( $\mathrm{IH}$ ) emerged after meal suspension as a biophysical, subjective sensation that coincided with a repeatedly recognizable physiological state of diminished energy availability by BG measurement. The physiological state recurred some times per day and suggested spontaneously energy intake in absence of visual, smell or word food cues [1]-[5]. At IH recognition, BG measurement confirmed the association with the previously assessed state of low energy availability (see later). A first study ascertained the recognition of hunger in the hospital lab. Seventy-two control adults and 64 trained adults completed the two month follow-up. We checked the learning by comparing the estimated BG and the BG measured by autoanalyzer [3]. Independent laboratories studied adults and confirmed our results [20] [21]. BG measurements were conceived as a protection from excessive BG lowering [1]. As a further protection, vegetables and fruit were suggested in an amount between 500 and 1000 grams per day over 8 years of age. This amount prevented BG depressions in hyperinsulinemic subjects who wanted to decrease body weight [17].

\subsection{Training Protocol}

1: Suspend meals for up to 48 hours,

2: Locate physical sensation of hunger,

3: Measure blood glucose concentration (BG),

4: Mentally associate the physical sensation with the BG concentration,

5: Begin with a meal of about $300 \mathrm{kcal}$,

6: Repeat 1-5 increasing the meal size in proportion to the desired inter-meal interval,

7: Repeat the above procedure for two weeks. At each appearance of physical hunger, compare the sensation and the measured BG with the previous sensations.

\subsection{Validity of a Portable Device for BG Measurements}

The training was accomplished by home BG preprandial measurements, with a portable device (a portable potentiometer for whole BG measurement with the exokinase method: Glucocard Memory; Menarini Diagnostics; Florence, Italy). The subject had to personally measure BG with the portable instrument against the autoanalyzer in the lab as he/she did at home. At blood sampling, we supervised the performance of the comparison. The autoanalyzer was checked every morning in comparison with the other 50 laboratories in Tuscany. A difference in BG from the mean had to remain within $1 \%$ every day. The heparinized blood sample for the autoanalyzer was immediately centrifuged and measured with the exokinase method. The meantime, the patient performed his/her measurements on the same blood sample by glucometer. The autoanalyzer obtained a mean \pm SD of $89.9 \pm 11.3$ $\mathrm{mg} / \mathrm{dL}(\mathrm{N}=85)$. Subjects measured $89.0 \pm 12.5 \mathrm{mg} / \mathrm{dL}$. The mean difference $(0.9 \pm 7.1)$ was not significant. On absolute values, the mean difference was: $5.7 \pm 4.3 \mathrm{mg} / \mathrm{dL}$ with no bias. This error is low compared to the spontaneous BG wavering of $10 \%$ every 12 minutes [22].

\subsection{Checking the Training}

Fat calories are burned and stored several times more slowly than non-fat calories [22]-[26], and there were large differences among the utilizations of fatty acids. We assumed that BG was representative, as an index, of total energy availability for body tissues in the studied, clinically healthy, subjects with carbohydrate intake between $50 \%$ and $60 \%$ of total energy intake.

The training consisted in BG measurements at hunger arousal, lasted two weeks, and one month later 64 trained and 72 control, untrained subjects attended the hospital lab before breakfast after an overnight fasting [3]. All subjects declared current presence or absence of hunger, and estimated BG (Figure 1). A glucose autoana- 
lyzer measured actual BG. All hungry subjects described hunger sensations as gastric emptiness or gastric pangs. In the hungry trained group, the mean estimated BG was $78.1 \pm 6.7$ and the mean measured value was $80.1 \pm$ $6.3 \mathrm{mg} / \mathrm{dL}$ This measured BG was significantly lower than the measurements in hungry control subjects (89.2 \pm $10.2 \mathrm{mg} / \mathrm{dL})$ and in not-hungry subjects of both trained $(90.0 \pm 6.6 \mathrm{mg} / \mathrm{dL})$ and control $(90.6 \pm 10.9 \mathrm{mg} / \mathrm{dL})$ groups. The absolute value of the difference between estimated and measured glucose (estimation error) in the hungry trained group (3.2 $\pm 2.4 \%$ of the measured value) was significantly lower than the one in the hungry control group $(16.7 \pm 11.0 \%)$. These findings prove that control (untrained) subjects do not reflect their biochemical condition when stating to be hungry and estimating BG. Trained subjects instead, show a low BG condition when hungry and estimate accurately their current energy availability. We repeated an uncontrolled study in children younger than three years of age [2]. In the hospital laboratory the autoanalyzer measured BG in 16 toddlers not demanding food before breakfast in comparison with 54 toddlers who were demanding food, all after training with 42 measurements at hunger arousal [2]. No demand was associated with a significantly higher BG than the condition of food demand $(96.3 \pm 10.5 \mathrm{mg} / \mathrm{dL}$ versus $74.6 \pm 7.7 \mathrm{mg} / \mathrm{dL} ; P=0.0001)$. Based on these studies, the initial demand (ID or IH) was conceived as a threshold phenomenon triggered by low energy availability in blood, indicated by low BG; normal activity is not inhibited by low energy. The intervention may be conceived as an abrupt weaning of the mother and child from the automatic, scheduled feeding to implement a habitual evaluation of time and amount of meal.

\subsection{Differences between Conditioned Hunger and Hunger after Meal Suspension (=IH)}

In the hospital lab, at the question on hunger, control, untrained subjects focused on food and developed gastroduodenal Pavlovian reflexes that are weaker and shorter than the sensations after eating suspension [3]. The main difference is at the sensation onset: either before focusing on food (after meal suspension) or after focusing on food (conditioned). Low BG can confirm the distinction (Figure 1).

\subsection{Effects of IHMP}

IHMP changes energy availability in blood and in all tissues. BG is a good index in people that draw more than $50 \%$ of their energy from carbohydrates. Preprandial BG informs also on energy balance, and the information on

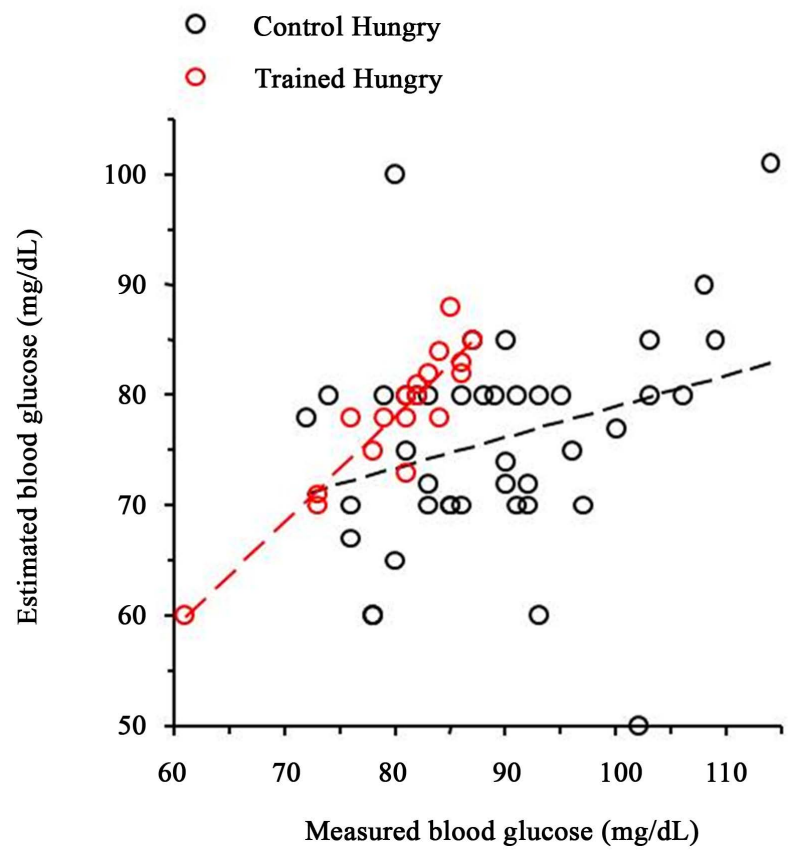

Figure 1. Subjects reporting hunger at the laboratory final investigative session. 42 untrained controls (black circles, $r=0.29$, NS) vs. 18 trained subjects (red circles, $r$ $=0.93, \mathrm{P}=0.0001$ ). Copyright $(C)$ 2006, Dove Medical Press Ltd., image courtesy of Ciampolini, M., et al. [3]. 
balance is very, very useful when the will to eat emerges. A mean in a sequence (pre-meal Mean BG) informs us on the habitual energy balance and on the maintenance of distance from fattening/insulin-resistance in that period [7]. In 120 adults at recruitment, Mean BG is stratified in ten strata with a small confidence interval around the mean $(3.8 \mathrm{mg} / \mathrm{dL})$ and values were stable after 5 months in 31 control, untrained adults (Confidence interval $=5.7 \mathrm{mg} / \mathrm{dL}$ ). In controlled studies during IHMP, we found significant decreases of:

1) Mean BG in controlled studies on 143 infants, and in 149 adults [2] [7] [13]; 2) plasma triglycerides in 9 undernourished infants [4]; 3) glycated hemoglobin in 120 adults [7]; 4) In our studies [2] [5] energy availability is associated with resting metabolic rate (RMR) and total daily expenditure (TDE). These values significantly decreased in 24 infants by indirect calorimetry and doubly labelled water [5]. The decreases in Mean BG and in RMR are not uniform among children and adults but are in positive significant correlation with the Mean BG at recruitment ( $\mathrm{r}=0.75 ; \mathrm{N}=89 ; \mathrm{P}=0.0001$, Figure 2 [7]); 5) About one third of investigated children had already at recruitment low Mean BG and did not decrease energy intake nor Mean BG after training in IHMP [2] [7]. This "freely chosen" low BG level at recruitment $(76.6 \pm 3.7 \mathrm{mg} / \mathrm{dL})$ is similar to the level maintained during IHMP [7]; 6) In sedentary people, this BG represents the fasting value associated with an even balance (maintenance of weight and insulin sensitivity) [7]. In controlled studies during IHMP, we found moreover significant decreases of: 7) SD of BG during a diary week [7]; 8) Triglycerides [1] [2] [5] [7]; 9) total cholesterol to HDL cholesterol ratio [7]; 10) diastolic blood pressure [7]; 11) number of days with diarrhea or abdominal pain [2] [7]. 12) Body weight and body mass index selectively in overweight adults and also normal-weight adults with high fasting mean BG (over about $82 \mathrm{mg} / \mathrm{dL}$ ) [13] [17]; 13) arm and 14) leg skinfold thickness in overweight adults and in subjects with high fasting mean BG [7] [13]; 15) increase of insulin sensitivity index, only in subjects with high fasting mean BG [7] [27]; 16) increase of insulinogenic index [7] [28]; 17) maintenance of body weight of lean children and adults who have low fasting mean BG [2] [7]; 18) fecal energy emission by bomb calorimetry [29].

\section{Results}

\section{Implementation of IHMP in Two Diabetic Subjects}

MM, 50 years old, came to our examination for obesity, BMI of 39, and for obesity increase of $1 \mathrm{~kg}$ per year in the previous ten years. He also complained abdominal pain every day. In the year 2010, he had IgA nephritis that resolved after two months. After recovery, an OGTT showed a BG AUC of $735 \mathrm{mg} / \mathrm{dL} / 3 \mathrm{~h}$, a BG peak of

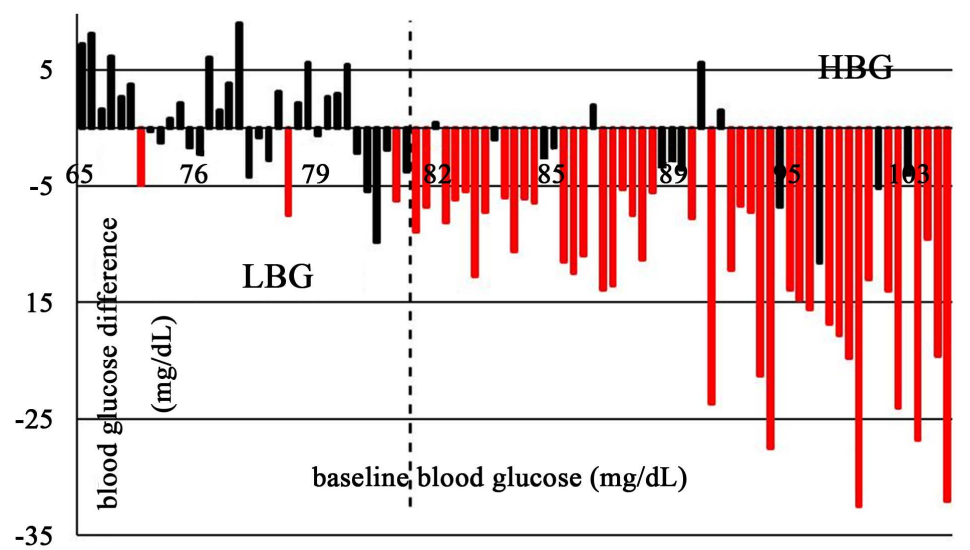

Figure 2. Decreases of mean pre-prandial BG after training versus Mean BG at recruitment for each trained subject. Notes: Abbreviations: BG, blood glucose; HBG, high blood glucose; LBG, low blood glucose. Column heights show Mean BG differences 5 months after recruitment in each trained subject. Significant increases are indicated by blue bars, significant decreases by red bars, and no significant changes by black bars. Mean BG is reported in sequentially increasing order at recruitment, not in linear correlation with segment length on the X-axis scale. The vertical dashed line indicates the most significant division between subjects who showed no Mean BG decrease after training (Low BG group, $\mathrm{n}=34$ ) and those who showed a significant decrease of Mean BG (High BG group, $n=55$; Chi-squared analysis: $P=0.00001$ ). This BG threshold at recruitment (demarcation point) is $81.8 \mathrm{mg} / \mathrm{dL}(4.54 \mathrm{mmol} / \mathrm{L})$ at recruitment. Subjects above this threshold affected most improvements in weight and insulin resistance. Copyright (C) 2011, Dove Medical Press Ltd., image courtesy of Ciampolini, M., et al. [7]. 
$233 \mathrm{mg} / \mathrm{dL}$, an insulin AUC of 242.2 (mU/L/3 h) and an insulin peak of $93 \mathrm{mU} / \mathrm{L}$. The insulin index by Matsuda was 3.35 and the insulinogenic index by Wiesli was 0.77 [27] [28]. After 5 years, we assessed a similar condition. The insulin response to glucose load was a little weaker. These results already show a diabetic condition. Fasting blood glucose was measured in three subsequent days $(127 \mathrm{mg} / \mathrm{dL}, 131 \mathrm{mg} / \mathrm{dL}$ and $128 \mathrm{mg} / \mathrm{dL}$; HbA1c $=6.0 \%$ ). We made routine blood examinations that were within normal limits except for uric acid $8 \mathrm{mg} / \mathrm{dL}$, triglycerides $162 \mathrm{mg} / \mathrm{dL}$, total cholesterol 246, HDL cholesterol 36 (thyroid hormones within normal range). We suggested no meal until arousal of gastric pangs or body weakness. The patient denied the arousal of any hunger sensation in the following 48 hours. We suggested 150 grams of chicken or fish plus $1 \mathrm{~kg}$ of vegetables or fruit per day. In the following months, the energy intake was around 400 - $500 \mathrm{kcal} / \mathrm{day}: 150$ grams of chicken or fish and $1 \mathrm{~kg}$ of not-starchy vegetables. Mean BG remained $99 \pm 12 \mathrm{mg} / \mathrm{dL}$ in four week diaries. In five comparisons with the autoanalyzer, the patient overestimated BG by $4 \mathrm{mg} / \mathrm{dL}$ with the own portable instrument. For eight months, the patient maintained about 400 - $500 \mathrm{kcal}$ energy intake per day but he never perceived gastric or weakness hunger [3]. On the contrary he became more physically active in the gym and working. His body weight decrease was $17 \mathrm{~kg}$ after ten months (13.8\% of the initial value).

UB, A similar subject was a watch technician, 60 years old, $84.9 \mathrm{~kg}$ of body weight, BMI 27.1. He was under treatment with metformin for NID diabetes. His BG was kept by metformin within the normal range even in the preprandial comparison with people under IHMP. He however experienced no hunger at all before recruitment. He stopped metformin. After meal suspension, he had no IH: neither gastric pangs nor weakness in the body or in mental activity. We tried to provide the about 50 nutrient principals and we tried to give energy in the least amount (non-starchy vegetables, up to one kg per day plus 150 grams of fish or chicken plus two coffee spoons of oil per day). 17 days after implementation of these instructions, the patient reported something which on interrogation resembled week gastric pangs. Afterwards, the arousal of IH allowed him increased intake, but no IH arousal allowed only vegetables and fish. After four months, the patient weighted $67.3 \mathrm{~kg}$, BMI 21.5. The body weight loss was $17 \mathrm{~kg}$, corresponding to a loss of $20 \%$ of his initial body weight (Tables $1-5$ ).

Table 1. Subject 1, anthropometric measures in a man of 50 years.

\begin{tabular}{cccccc}
\hline & Base & $3 \mathrm{~m}^{2}$ & $10 \mathrm{~m}$ & $12 \mathrm{~m}$ & \% Decrease \\
\hline Body weight $(\mathrm{kg})$ & 123.5 & 113 & 107 & 106.5 & 13.4 \\
Height $(\mathrm{cm})$ & 178 & & & 178 & 0 \\
BMI $^{1}$ & 38.8 & 35.6 & 33.7 & 33.6 & 13.4 \\
Waist circumf. (cm) & 131 & & 113 & & 13.7 \\
Hip circumf. (cm) & 122 & & 115 & & 5.7 \\
\hline
\end{tabular}

${ }^{1}$ Body weight (kg)/Square height $(\mathrm{m}) ;{ }^{2} \mathrm{~m}=$ months after baseline.

Table 2. Subject 1 at baseline and during the follow-up. Composition, compliance and effects of training (IHMP) on diary reports and anthropometry.

\begin{tabular}{|c|c|c|c|c|c|c|}
\hline & Base & $1 \mathrm{~m}$ & $2 \mathrm{~m}$ & $7 \mathrm{~m}$ & $12 \mathrm{~m}$ & Predinner BG \\
\hline Energy intake $^{1}$ & 1130 & 603 & 673 & 473 & $702 \pm 120$ & \\
\hline Mean BG $(\mathrm{mg} / \mathrm{dL})^{2}$ & $99.4 \pm 12.2$ & $99.2 \pm 12.8$ & $99.6 \pm 8.0$ & $99.3 \pm 12.8$ & $96.0 \pm 13.6$ & $79.3 \pm 5.1^{3}$ \\
\hline Hb1c (\%) & 6 & 5.8 & 5.7 & 5.8 & 5.3 & \\
\hline Insulin AUC (mU/L/3h) ${ }^{4}$ & 242 & & & 247 & & \\
\hline Insulin peak (mU/L) & 93 & & & 64 & & \\
\hline Insulin sens & 3.35 & & & 3.13 & & \\
\hline Insulinogenic index & 0.77 & & & 0.76 & & \\
\hline BG AUC (mg/dL/3h) $)^{5}$ & 735 & & & 826.5 & & \\
\hline BG Peak (mg/dL) & 233 & & & 211 & & \\
\hline Tot Cholest (mg/dL) & 246 & 247 & 240 & 207 & & \\
\hline HDL Cholest (mg/dL) & 36 & 41 & 41 & & 51 & \\
\hline Triglycerides (mg/dL) & 162 & 167 & 125 & & 134 & \\
\hline
\end{tabular}

${ }^{1} \mathrm{Kcal} / \mathrm{day} ;{ }^{2}$ Mean of 21 preprandial blood glucose measurements by portable device reported by diary; ${ }^{3}$ Mean of 8 blood glucose measurements before the dinner reported in the diary of $12{ }^{\text {th }}$ month; ${ }^{4} \mathrm{AUC}=$ Area under insulin curve during OGTT; ${ }^{5}$ AUC= Area under BG curve during OGTT. 
Table 3. Subject 2. A 60-year old man with type-2 diabetes taking metformin.

\begin{tabular}{cccccc}
\hline & weakness & IH & Food intake & Pre-meal BG \\
\hline BREAKFAST: & No & No & Half-strength milk $100 \mathrm{ml}+$ bread $25 \mathrm{~g}$ + honey $5 \mathrm{~g}$ & $\mathbf{8 1}$ \\
LUNCH: & No & No & $\begin{array}{c}\text { Spaghetti } 90 \mathrm{~g} \text {, Tomato } 150 \mathrm{~g} \text {, cucumber } 270 \mathrm{~g}, \\
\text { olive oil } 7 \mathrm{~g} \text {, parmesan } 15 \mathrm{~g} \text {, Apple } 150 \mathrm{~g}\end{array}$ & $\mathbf{7 9}$ \\
DINNER: & No & No & Bread $80 \mathrm{~g}+$ chicken-breast $120 \mathrm{~g}$ + olive oil $7 \mathrm{~g}+$ pear 200 g & $\mathbf{7 7}$ \\
Energy intake (kcal/d) & & & 1136 & \\
\hline
\end{tabular}

Notice satisfactory metformin-induced pre-meal BG maintenance although he never reports hunger.

Table 4. Low food intake in the subject 2 during 4 months of hunger recognition and metformin cessation.

\begin{tabular}{ccccc}
\hline & Weakness & Gastric pangs & Food intake & Pre-meal BG \\
\hline Breakfast: & No & No & Coffee $30 \mathrm{ml}$ & $\mathbf{8 0}$ \\
Lunch: & No & No & Anchovy $70 \mathrm{~g}$ + salad 180 + olive oil 3 g & $\mathbf{7 6}$ \\
Dinner: & No & Yes/No & Anchovy $75 \mathrm{~g}+$ Tomato 350 + olive oil 4 g & $\mathbf{7 4}$ \\
Energy intake $(\mathrm{kcal} / \mathrm{d})$ & & & 333 & \\
\hline
\end{tabular}

Table 5. Subject 2, anthropometric measures.

\begin{tabular}{cccc}
\hline & June 2010 & Nov 2010 & \% Decrease \\
\hline Body weight (kg) & 84.9 & 67.3 & $20.7 \%$ \\
Height (cm) & 177 & \\
BMI $^{1}$ & 27.1 & 21.5 \\
Waist Circumf. (cm) & 103 & 85 \\
Hip Circumf. (cm) & 105 & 94.5 \\
\hline
\end{tabular}

${ }^{1}$ BMI = Body Weight $(\mathrm{kg}) /$ Square Height $(\mathrm{m})$.

\section{Discussion (Project Hypothesis)}

The two diabetic patients object of present report, were observed within the recruitment program that we described in the section "Studies in Adults". We treated them with the usual IH training. In past investigations, all children and all adults manifested IH arousal after meal suspension up to 48 hours. Sometimes, adults denied any perception of $\mathrm{IH}$ in their past life. Also in these adults, IH arouse as a spontaneous event after hours or a day of no meal consumption. Our interpretation was that these adults ate by conditioned reflexes. Their past arousals of hunger were conditioned and two days of meal suspension was sufficient to evoke the arousal of Initial Hunger (IH). On the contrary, the two diabetic patients of the present report denied any hunger arousal and maintained either high BG (subject 1) or, under metformin (subject 2), normal preprandial BG before the meal, respectively (99 mg/dL, $95 \mathrm{mg} / \mathrm{dL}$ after correction in subject 1; 74 to $80 \mathrm{mg} / \mathrm{L}$ in subject 2, Table 2 and Table 4). This means that their initial body weight was associated with energy stores so large that covered $60 \%$ to $70 \%$ of daily metabolic expenditure by fatty acids delivery into blood, $30 \%-60 \%$ being covered by daily intake. The width of the exit gate from fatty stores is correlated to the amount of stored fat (percentage of replenishment of fatty cells) [22]-[26]. Both patients maintained happy physical and mental activity and both improved their blood examinations. These facts and BG measurements before meals suggest that both patients maintained an optimal energy availability. Presumably, both maintained sufficient availability of protein, mineral and vitamins. A copious and variated consumption of vegetables and a limited consumption of animal food (100 to 200 grams per day) may offer more essential amino-acids, vitamins and minerals for life than a diet rich in carbohydrates or fats. Not starchy vegetables between half and one kg [1] [17] and 100 - 200 grams of chicken or fish might cope with this food project. Energy intake from carbohydrates or fat would be a useless energy surplus to maintain the 
diabetic state. This study suggests that the NIDD patient requires an adequate loss of fatty stores and of the associated decrease of fatty acids influx into blood to recover low BG $(76.6 \pm 3.7 \mathrm{mg} / \mathrm{dL})$ and hunger sensations. A similar attempt in NIDD diabetics failed in preventing cardiovascular untoward events [30], but the body weight decrease was only $7 \%$ of initial body weight. The expertise on meal by meal dynamic maintenance of energy balance [31] might be necessary for further body weight loss and for a long period maintenance of the body weight loss [14].

Body weight loss is rather easy in NIDD diabetics because painful hunger and low BG levels do not emerge. This is a suggestive hypothesis that can be thoroughly demonstrated after successful repetition of present achievements in 19 further patients out of 20 patients to be investigated. This next investigation implies no harms or risks. In doubts, energy availability may be checked three times a day at the lowest points during the day by BG measurements before meals. The primary objective may be the achievement of the normal BG condition, i.e., a preprandial decrease to $76.6 \pm 3.7 \mathrm{mg} / \mathrm{dL}$. The body weight loss may be between $10 \%-20 \%$. After this achievement the NIDD patients do not differ from the many healthy subjects we followed. An IH meal pattern allows them normal, healthy and long life without any overall inflammation and drug intake. That means remaining exposed to the development of fattening/insulin resistance as everybody. An ordinate awareness on these achievements and on current BG may unremittingly contrast meal by meal positive energy balance.

\subsection{Limitation of the Study}

The major limitation we feel in our studies is the subjective nature of the found proper limitation in intake. There will be subjects that deny arousal of hunger or arousal of IH when there actually is an arousal. BG measurements reveal this occurrence. On the other hand, we encountered few subjects that asserted to be hungry with high BG. We began to explore this high preprandial BG in subjects exposed to intense, outdoor physical work in a cold climate [7]. This association resulted to be significant. The worst problem may be the inadvertent increase in preprandial BG after years and years of correct use of IHMP, We suggest periodical BG verifications.

\subsection{Conclusion}

Fattening ends when insulin production becomes insufficient to further store fat during a positive energy balance. Energy influx from storage tissues largely covers energy expenditure, BG does not decrease to $76.6 \pm 3.7 \mathrm{mg} / \mathrm{dL}$ and hunger does not arise before meals. A conspicuous body weight loss restores the preprandial recovery of both low preprandial BG and arousal of hunger sensations. An awareness on own current BG may be partly present in Western Country people: a further diffusion seems necessary to successfully deal with the current abundance of energy dense food.

\section{Acknowledgements}

The Author acknowledges the indispensable collaboration in writing with David Lowel-Smith (NZ) and Riccardo Bianchi (NY), and the strategic, statistical support by Cutberto Garza (Rector, Boston College), GiulianoParrini (Professor of Physics, Firenze) and Andrea Giommi (Professor of Statistics, Firenze).

The here summarized researches were supported by the Italian Ministry of University, Research, Science and Technology grants for the years 1998-2002 and by ONLUS Nutrizione e Prevenzione, Firenze, for the years 2003-2012.

This review has been shown in: "Modifying Eating Behavior: Novel Approaches for Reducing Body Weight, Preventing Weight Regain and Reducing Chronic Disease Risk” ASN’s Annual Meeting \& Scientific Sessionsat Experimental Biology 2014, April 26-30.

\section{Conflict of Interests}

No conflicts of interest.

\section{References}

[1] Ciampolini, M., Vicarelli, D. and Seminara, S. (1990) Normal Energy Intake Range in Children with Chronic Non-Specific Diarrhea. Association of Relapses with the Higher Level. Journal of Pediatric and Gastroenterology \& Nutrition, 11, 342-350. http://dx.doi.org/10.1097/00005176-199010000-00010 
[2] Ciampolini, M. (2012) Requested Meals versus Scheduled Meals. International Journal of General Medicine, 5, 345-343. http://dx.doi.org/10.2147/IJGM.S29889

[3] Ciampolini, M. and Bianchi, R. (2006) Training to Estimate Blood Glucose and to Form Associations with initial Hunger. Nutrition \& Metabolism, 3, 42. http://www.nutritionandmetabolism.com/content/3/1/42 http://dx.doi.org/10.1186/1743-7075-3-42

[4] Ciampolini, M., Bianchi, R. and Sifone, M. (2014) “Initial Hunger” for All? A Study on Undernourished Infants. Journal of Pediatrics \& Neonatal Care, 1, Article ID: 00008. http://dx.doi.org/10.15406/jpnc.2014.01.00008

[5] Ciampolini, M., Brenna, J.T., Giannellini, V. and Bini, S. (2013) Interruption of Scheduled, Automatic Feeding and Reduction of Excess Energy Intake in Toddlers. International Journal of General Medicine, 6, 39-47. http://dx.doi.org/10.2147/IJGM.S39946

[6] Ciampolini, M. (2013) Interruption of Automatic Feeding, of Fattening and Associated Immune Deficiency. Recent Research Developments in Nutrition, 9.

[7] Ciampolini, M. and Sifone, M. (2011) Differences in Maintenance of Mean Blood Glucose (BG) and Their Association with Response to “Recognizing Hunger”. International Journal of General Medicine, 4, 403-412. http://dx.doi.org/10.2147/IJGM.S19035

[8] Ciampolini, M., Lovell-Smith, H.D., Kenealy, T. and Bianchi, R. (2013) Hunger Can Be Taught: IHMP Regulates Eating and Improves Energy Balance. International Journal of General Medicine, 6, 465-478. http://www.dovepress.com/articles.php?article_id=13355

[9] Ciampolini, M. and Lovell Smith, D. (2014) Self-Regulation of Food Intake and Energy Balance. A Handbook. Lambert Academic Publishing, Saarbrücken, 35.

[10] Ciampolini, M., Becherucci, P., Vicarelli, D., Seminara, S., Bini, S. and Grifi, G. (1991) Decrease in Serum IgE Associated with Limited Restriction in Energy Intake to Treat Toddler's Diarrhea. Physiology \& Behavior, 49, $155-160$. http://dx.doi.org/10.1016/0031-9384(91)90248-M

[11] Ciampolini, M., Bini, S., Giommi, A., Vicarelli, D. and Giannellini, V. (1994) Same Growth and Different Energy Intake in Chronic Non-Specific Diarrhea Children in a Four-Year Period. International Journal of Obesity, 18, 17-23.

[12] Ciampolini, M., Borselli, L. and Giannellini, V. (2000) Attention to Metabolic Hunger and Its Effects on Helicobacter pylori Infection. Physiology \& Behavior, 70, 287-296. http://dx.doi.org/10.1016/s0031-9384(00)00273-0

[13] Ciampolini, M., Lovell-Smith, D. and Sifone, M. (2010) Sustained Self-Regulation of Energy Intake. Loss of Weight in OW Subjects. Maintenance of Weight in Normal-Weight Subjects. Nutrition \& Metabolism, 7, 4. http://www.nutritionandmetabolism.com/content/7/1/4 http://dx.doi.org/10.1186/1743-7075-7-4

[14] Ciampolini, M., Lovell-Smith, D., Bianchi, R., de Pont, B., Sifone, M., van Weeren, M., de Hahn, W., Borselli, L. and Pietrobelli, A. (2010) Sustained Self-Regulation of Energy Intake: Initial Hunger Improves Insulin Sensitivity. Journal of Nutrition and Metabolism, 2010, Article ID: 286952. http://www.hindawi.com/journals/jnume/aip.286952.html

[15] Ciampolini, M. (2012) Eliciting Clear-Cut Initial-Hunger at Proper Time. OMICS Publishing Group, Hyderabad.

[16] Ciampolini, M. (2015) Physiology versus Pharmacology. Journal of Pediatrics and Neonatal Care, 3, 00121.

[17] Ledoux, T., Gallagher, M.R., Ciampolini, M. and Sampson, M. (2014) Biofeedback Enhanced Lifestyle Intervention: Exploring the Experience of Participants in a Novel Intervention for Disinhibited Eating and Obesity. Open Journal of Preventive Medicine, 4, 779-788. http://dx.doi.org/10.4236/ojpm.2014.410088

[18] Ciampolini, M., de Haan, W., de Pont, B. and Borselli, L. (2001) Attention to Metabolic Hunger for a Steadier (SD Decrease to 60\%), Slightly Lower Glycemia (10\%), and Overweight Decrease. Appetite, 37, 123-172.

[19] Armitage, P. and Berry, G. (1994) Statistical Methods in Medical Research. 3rd Edition, Blackwell Scientific Publications, Oxford.

[20] Jospe, M.R., Brown, R.C. and Roy, M. (2015) Adherence to Hunger Training Using Blood Glucose Monitoring: A Feasibility Study. Nutrition \& Metabolism, 12, 22. http://dx.doi.org/10.1186/s12986-015-0017-2

[21] De Graaf, C., Blom, W.A.M., Smeets, P.A.M., Stafleu, A. and Hendriks, H.F.J. (2004) Biomarkers of Satiation and Satiety. The American Journal of Clinical Nutrition, 79, 946-961.

[22] Campfield, L.A. and Smith, F.J. (2003) Blood Glucose Dynamics and Control of Meal Initiation: A Pattern Detection and Recognition Theory. Physiological Reviews, 83, 25-58. http://dx.doi.org/10.1152/physrev.00019.2002

[23] Swinburn, B.A. and Ravussin, E. (1994) Energy and Macronutrient Metabolism. Baillière’s Clinical Endocrinology and Metabolism, 8, 527-548. http://dx.doi.org/10.1016/S0950-351X(05)80285-X

[24] Westerterp, K.R. (2004) Diet Induced Thermogenesis. Nutrition \& Metabolism, 1, 5. http://dx.doi.org/10.1186/1743-7075-1-5

[25] Van Wymelbeke, V., Himaya, A., Louis-Sylvestre, J. and Fantino, M. (1998) Influence of Medium-Chain and Long- 
Chain Triacylglycerols on the Control of Food Intake in Men. The American Journal of Clinical Nutrition, 68, 226234.

[26] Summers, L.K.M., Barnes, S.C., Fielding, B.A., Beysen, C., Ilic, V., et al. (2000) Uptake of Individual Fatty Acids into Adipose Tissue in Relation to Their Presence in the Diet. The American Journal of Clinical Nutrition, 71, 1470-1477.

[27] Matsuda, M. and DeFronzo, R.A. (1999) Insulin Sensitivity Indices Obtained from Oral Glucose Tolerance Testing: Comparison with the Euglycemic Insulin Clamp. Diabetes Care, 22, 1462-1470. http://dx.doi.org/10.2337/diacare.22.9.1462

[28] Wiesli, P., Schaffler, E., Seifert, B., Schmid, C. and Donath, M.Y. (2004) Islets Secretory Capacity Determines Glucose Homoeostasis in the Face of Insulin Resistance. Swiss Medical Weekly, 134, 559-564.

[29] Ciampolini, M., Giannellini, V. and Butte, N. (2001) Recognition of Depletion Manifestations (Bearable Hunger) in Infants by Trained Caregivers and Lower Fecal Energy Loss (Abstract). SSIB Annual Meeting, Philadelphia, 26-30 June 2001, 38.

[30] The Look AHEAD Research Group (2013) Cardiovascular Effects of Intensive Lifestyle Intervention in Type 2 Diabetes. The New England Journal of Preventive Medicine, 369, 145-154. http://dx.doi.org/10.1056/NEJMoa1212914

[31] Ciampolini, M. Ed., (2011) The Meal by Meal Dynamic Balance of Energy in Blood. Research Signpost, 37/661(2), Vazhappalli Jn., Fort Post Office, Trivandrum-695 023, Kerala, India. 